http://dx.doi.org/10.18232/alhe.1057

Reseña

\title{
José Antonio Piqueras y Guy Pierre (coords.), La irrupción del imperio: el Caribe y América Central bajo el dominio del capital norteamericano, 1898-1940, México-España-Argentina, Akal, 2018, 320 pp.
}

Carlos Marichal $^{1,} *$ (D) 0000-0002-1479-7239

${ }^{1}$ El Colegio de México, México.

* Correspondencia: cmari@colmex.mx

Este libro de siete ensayos muy bien escritos por historiadores destacados de Cuba, Haiti, Santo Domingo, Puerto Rico, Colombia y México, representa un avance importante en la historiografía caribeña y latinoamericana, pero además, dialoga estrechamente con la norteamericana y al mismo tiempo renueva una serie de debates importantes. Ello se hace manifiesto en el ensayo que abre el libro, "el nacimiento del imperio norteamericano", por Jose Antonio Piqueras -historiador español- quien escribe "Imperialismo [...] es en el siglo XxI una de esas palabras condenadas a la postración”. Sin embargo, una cuidadosa lectura del libro tiende a sugerir que los editores del volumen desean sacar a este término y concepto del olvido y volver a hacer que camine -quizá con ropa nueva y por caminos diferentes- para iluminar la historia del Caribe desde ángulos novedosos, especialmente en los primeros cuatro decenios del siglo xx.

En su ensayo Piqueras realiza una doble tarea muy útil al repasar tanto la teoría como la historiografía del concepto de imperialismo (y del antiimperialismo), al tiempo que resume de manera paralela una serie de puntos medulares de la historiografía del Caribe en las coyuntas claves de la expansión del imperialismo de Estados Unidos en la región en el periodo de 1898-1940. Sin duda, el interrogante más importante que plantea este ensayo y, en cierto sentido, todo el libro consiste en explorar la pregunta żcuándo comenzó a forjarse el imperio americano en la región? Su respuesta nos remite esencialmente a la guerra de 1898, cuando las tropas norteamericanas ocuparon Cuba, que fue convertido en una especie de protectorado de Estados Unidos, al tiempo que invadieron
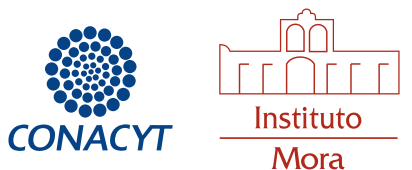
y transformaron a la isla Puerto Rico, en una simple colonia. Luego siguieron otras intervenciones por parte de militares y banqueros de Estados Unidos, que incluyeron las operaciones para forzar la creación de Panamá en 1903 y establecer la tutela de Estados Unidos sobre este nuevo país, desgajado de Colombia, así como las largas intervenciones militares de los marines en Santo Domingo, Haití y Nicaragua que arrancaron en los años de 1914-1915.

La temática concreta del libro nos remite específicamente al imperialismo norteamericano en el Caribe en el periodo estudiado, pero en verdad evoca una historia más larga. Recordemos que, desde su independencia en 1783, las trece colonias de Estados Unidos tuvieron una conciencia de las potencialidades de la expansión de una "república imperial”. El primer paso comenzó con la expansión por el sur, con la compra de Luisiana en 1803 y luego con la adquisición de las Floridas en 1819. Casi al mismo tiempo, los colonos granjeros que se movieron hacia el oeste medio -Ohio, Indiana, Illinois, Kansas, Missouri- lo hicieron con base en la guerra y expulsión de pueblos indios originarios. En los años siguientes del siglo xIx -y una vez poblada de la misma manera las extensas tierras de la antigua Luisiana que vendría a ser conocido como el Deep South-, quedaba el reto de tomar control de las tierras del gran norte mexicano. De allí surgió la invasión y guerra contra México en los años de 1846-1848, realizada en nombre de la expansión de la esclavitud y del dominio territorial hacia el oeste. De hecho, esta guerra en contra de México fue en muchos sentidos otro capítulo fundamental del temprano "imperialismo" norteamericano, que sus promotores bautizaron como Manifest Destiny.

Esta compleja historia ha sido objeto en los últimos decenios de un importante proceso de revisionismo por algunos historiadores del norte, cada vez más críticos con los mitos y estereotipos de la creación de esa nación, ya que esta fue, en realidad, resultado de un proceso violento de expropiación de la población originaria indígena, del sometimiento de los mexicanos y de la explotación de los afroamericanos. Dicha tarea revisionista es cada vez más necesaria, pues las condiciones sociales y demográficas del vecino del norte han cambiado de manera profunda, si bien las clases dirigentes apenas quieren reconocerlas. La pertenencia de este enfoque, que habla sobre la historia social de los sectores expropiados en el siglo XIX en Estados Unidos, se confirma en estudios recientes que demuestran que hoy en día la población blanca (no hispana) en Estados Unidos es ya apenas la mitad del total en ese país: los hispanos, negros y asiáticos, cada vez más numerosos, han cambiado el perfil demográfico del conjunto nacional. La desazón y el miedo que ello genera ayuda a explicar las fuerzas subyacentes del apoyo de tantos votantes blancos a las políticas racistas de Donald Trump. Pero quedan otros mitos que requieren revisarse de la historia "blanca" de Estados Unidos y, en particular aquellos que se refieren a las relaciones con los demás pueblos y países de las Américas. Y uno muy importante es la que trata este libro sobre el Caribe.

En el libro que reseñamos se plantean interrogantes esenciales: ¿pueden considerarse las intervenciones norteamericanas en el Caribe desde 1898 en adelante como otra faceta del Manifest Destiny?, ¿̇o fueron una especie de extensión marítima de la idea de la "frontera" norteamericana (a lo Fredrick Turner), como eje de la historia de ese país?, ¿̇o puede considerarse que la expansión sobre el Caribe fue reflejo del imperialismo tal como lo describieron y teorizaron Hobson, Hilferding o Lenin?, o ¿fue resultado del dollar diplomacy, expresión adoptada por la primera generación de antiimperialistas norteamericanos y latinoamericanos desde los años de 1920?

Los autores del presente libro valoran, pero también critican y cuestionan aspectos de estos planteamientos por lo que consideran que hay que ahondar y proponer enfoques renovados: no se desentienden absolutamente de los clásicos, pero proponen profundizar en el tema del imperialismo en los primeros cuatro decenios del siglo xx a partir de estudios particulares. Argumentan que 
falta, por tanto, mucho más trabajo futuro para completar y ahondar en esta problemática y, de hecho, los diferentes ensayos de este libro reflejan un esfuerzo sistemático y prolongado realizar dicha tarea desde una perspectiva histórica.

No podemos abordar aquí en esta breve reseña todos los temas analizados en los siete ensayos en este libro, pero sí deseamos hacer mención de algunos puntos que parecen especialmente significativos y que puedan estimular la lectura del presente volumen. El volumen reúne una serie de trabajos eruditos y sugerentes realizados por un conjunto de investigadores del "Sur", entre los cuales se cuentan historiadores del Caribe, de Centroamérica y Colombia, de México y, como no, de España. Para comenzar se incluye el ensayo de Alejandro García Álvarez, connotado historiador cubano, autor de libros sobre la historia de la United Fruit en Cuba, y del gran libro de Caminos para el azúcar, historia de los ferrocarriles en la isla, que escribió a cuatro manos con Oscar Zanetti; Álvarez es también autor de otro libro fundamental, La gran burguesía comercial en Cuba 1899-1920. En su ensayo analiza un tema que sólo recientemente ha despertado interés, que consiste en reconstruir la historia bancaria de Cuba en el primer tercio del siglo xx. En particular, centra su atención en el papel del National City Bank que llegó a ser la entidad financiera dominante y promotor de numerosas inversiones en Cuba. Desde 1914, este banco rápidamente estableció una red de sucursales en la isla que le sirvieron para establecer su posición de poder bancario, pero sobre todo pudo sacar provecho de la gran crisis financiera en Cuba en 1921, que le permitió crear un imperio de compañías azucareras, muchas de ellas absorbidas por el banco a partir de las quiebras de cientos de clientes cubanos en esa vorágine.

El National City Bank fue, en verdad el verdadero pionero del imperialismo financiero norteamericano en el Caribe ya que operó no sólo en Cuba, sino también en Haití, donde absorbió el Banque Nationale d'Haiti desde 1914, y en Santo Domingo donde absorbió el Banco Nacional. El National City se dedicó a la banca comercial - como uno de los primeros bancos norteamericanos a operar en el exterior a partir de la legislación de 1914 que permitió el establecimiento de sucursales en el exterior. Sus competidores más importantes fueron el Bank of Boston, así como un consorcio de bancos liderados por Morgan -que tuvo menos éxito- y el Royal Bank of Canada que tuvo aún más sucursales en la región del Caribe, y que merecería un estudio más a fondo. El papel del National City Bank, es revisado en el caso de Santo Domingo en el ensayo de Roberto Cassá, director del Archivo General de la Nación de Santo Domingo y autor de libros como la Historia social y económica de la República Dominicana y capitalismo y dictadura. En su ensayo, Cassá ofrece una excelente síntesis de cómo aumentaron los intereses norteamericanos en Santo Domingo, y especialmente la expansión de las empresas de azúcar entre 1880 y 1930 . Al final, su ensayo centra la atención en el sector financiero por lo que titula su ensayo "de la empresa individual al conglomerado corporativo" para referirse al caso de el National City. Hoy este banco se llama Citicorp y es uno de los diez bancos más poderosos del mundo.

En otra sección del libro, Iyari Ríos Gonzalez y Annie Santiago, profesoras de la Universidad de Puerto Rico, Río Piedras, ofrecen trabajos sobre la historia económica y política de la isla y en este libro contribuyen con un ensayo que aclara cómo desde 1898 y la Ley Foraker y la Ley Jones se forjó un creciente control de la economía de la isla por empresas norteamericanas, especialmente en la producción y comercialización del azúcar. Sigue, luego, un ensayo de Guy Pierre, presidente honorario de la Asociación de Historia Economica del Caribe y editor de Historia económica del Caribe, 1880-1950 y autor de La crisis de 1929 en Haití: una perspectiva de larga duración. Realiza un estudio estupendo de la literatura histórica y económica del impacto de las inversiones norteamericanas en la economía haitiana en los primeros decenios del siglo xx. Su ensayo es 
una pequeña joya de historia intelectual del periodo, analizando los escritos de intelectuales norteamericanos, de autores liberales y nacionalistas haitianos y franceses, y de autores marxistas y dependendistas sobre esta temática.

Una contribución asaz diferente pero paralela es la de Salomón Kalmanowitz, profesor emérito de la Universidad de Bogotá Jorge Tadeo Lozano y autor de numerosas obras clásicas de la historia económica de Colombia. Analiza las finanzas de Panamá en las primeras décadas del siglo xx, lo que en realidad le permite esbozar un ser una pequeña y sintética historia económica de Panamá en este periodo, incluyendo el análisis de las tendencias del comercio, fiscalidad, inversiones y tasas de crecimiento. Sugiere que los marcos institucionales (neocoloniales) de la flamante república, tutelada por Estados Unidos, limitaron el desarrollo doméstico.

Finalmente, el libro que reseñamos incluye un ensayo de Natalia Vargas Escobar, profesora del Tecnológico de Monterrey, campus Ciudad de México, quien analiza el papel del Eximbank en Centroamérica y el Caribe entre 1934 y 1954. Su información es detallada, siendo resultado de una investigación directa en los archivos históricos del banco en Washington. La información que proporciona es de gran interés, pero al finalizar su ensayo, queda flotando una interrogante en el aire, pues no queda realmente claro si el transito al New Deal adoptado por la administración de Franklin Delano Roosevelt desde 1932 contribuyó a facilitar algunas políticas de apoyo a empresas nacionales latinoamericanas, marcando un cambio de rumbo, o si, finalmente, este banco público era simplemente un instrumento para promover las exportaciones de corporaciones norteamericanas a la región.

En resumidas cuentas, los coordinadores del presente volumen, José Antonio Piqueras y Guy Pierre han logrado culminar un proyecto de investigación multifacético sobre el imperialismo económico y financiero norteamericano en el Caribe con un libro de muy buena factura. Después de la lectura, yo me llevo más preguntas que respuestas a casa, pero también considero que se trata de un texto al cual uno puede recurrir repetidamente para ahondar en los temas de gran interés que cubre. 